\title{
Recovery in Mental Health Care with the Aid of Photo-stories: An Action Research Based on the Principles of Hermeneutic Photography
}

\author{
Jan Sitvast \\ Master Program in Advanced Nursing Practice, The University of Applied Sciences Hogeschool Utrecht (HU), Netherlands
}

Copyright $(2015$ by authors, all rights reserved. Authors agree that this article remains permanently open access under the terms of the Creative Commons Attribution License 4.0 International License

\begin{abstract}
Our aim was to develop and evaluate an intervention that can be used in recovery oriented care to promote recovery processes and goals as found in the CHIME framework [1]. Using the Appreciative cycle and principles from the MRC-Framework for the development and Evaluation of complex interventions an intervention with photography has been designed and tested on 3 long stay wards of a mental health care hospital. 15 Service users participated and were photographed during 4 sessions. The intervention built on the expertise that already existed about rehabilitation approaches; especially the Strengths approach [2] and the findings from earlier studies into hermeneutic photography by the author. The intervention proved to inspire hope and meaning giving in service users and contributed to a transformation of relationships between service users and their mentor nurses. These relationships became more reciprocal and equal. The intervention yielded opportunities for service users to express their wishes and values in life. In this way they made a representation of the persons who they are. The photographs probably contribute to a greater self-esteem of the service users and may inspire them to use the action and what it meant to them for further recovery. The intervention put the service user in the lead and contributed to more mutuality in the relationship with the mentor nurse.
\end{abstract}

Keywords Hermeneutic Photography, Recovery, Recovery Oriented Care, Empowerment

\section{Introduction}

This article is about a health care intervention for persons with severe mental illness, who are dependent on care and hospitalised in long stay wards of a large psychiatric hospital in the eastern part of the Netherlands. These 'service users' as they are often called, were diagnosed with schizophrenia and/or mood disorders in $80 \%$ of all cases (autism and other disorders counting for the remaining 20\%). The psychic condition of the service users who participated in the intervention was stable for the most of the time, meaning that they were not harassed by hallucinations and agitations to a large degree. The intervention is based on hermeneutic photography. Hermeneutic photography aims at using photography as a medium for meaning making and story-telling $[3,4]$.

As health care professionals we witness how persons with a severe mental illness (abbrev. as SMI: see also list with abbreviations) struggle to salvage a life from the constraints and limitations of the illness that affect them. A person has an illness, but is not the illness. We believe that even when one has symptoms that make daily life hard, then one can still have a valued life that is a life with activities that one thinks important, valuable or just pleasant to do. This reclaiming one's life from the impact a mental illness has on one's self-esteem we call 'recovery'. Recovery is a new paradigm in mental health care and the positive psychology. It is also a movement that has risen from the peer groups in which patients organised themselves in order to tell their story and help each other.

"Recovery is something that clients must do themselves. It is a search for answers to the question how to cope with the psychic handicap, how to get a grip on it and how to take direction of life again in one's own hands. Recovery is not the same as cure. The psychological problems do not go away, but compel someone into a long learning process. " [5].

Recovery is an individual learning process. How can caregivers support or facilitate clients in this process that ultimately they have to go for themselves? Recovery Facilitating Care is not new in the Netherlands; it can build on the rehabilitation-approach that has been the guiding principle for the support of clients in chronic care from the beginning of the nineties of the twentieth century. What is new, however, is the focus on the resilience of clients and how clients utilise this power: the so called Strengths 
Approach [2]. Utilizing their resilience clients will be better able to answer the issue how to take life in their own direction. First making an inventory of one's own strengths can be useful. Strengths are more than talents and skills alone. There is strength in strong opinions and convictions as is also the case with memories of events in life that were experienced as good. A motivational power can be attributed to a longing to become someone different from who you are now. The same may be true for a wish to engage in a job or a hobby. Last but not least there is the support that clients experience from relatives, fellow men and caregivers. This support often gives clients the power to go on in life. Ego-documents of persons who report on their own recovery-trajectory describe how important it was that there were people who did not lose faith and kept believing in them, even in the darkest hours of crisis [6]. We noticed however that people who are hospitalised on long stay wards in mental health institutes tend to have lost much of their social network and also have lost the hope to realize the wishes and ambitions they had before the onset of their illness. Through a process of self-stigmatisation they have gradually adjusted their self-esteem to match the role of dependent patients needing care and hospitalisation $[7,8]$. This phenomenon is an extra challenge for recovery facilitating care serving persons with severe mental illness who are hospitalised. Although the research on recovery and recovery facilitating care is growing in recent years, the focus until now has been on guiding principles and goals and there is less consensus about the concrete components of care that are most effective in achieving recovery goals, especially in long term institutional mental health care [9]. As goals for recovery we focused on hope and meaning giving, which are considered important process related outcomes in the CHIME-framework for personal recovery as formulated by Leamy et al. [1].

Table 1. Recovery processes (Leamy et al, 2011): in bold (second column) the goals the intervention focuses on.

\begin{tabular}{|c|c|}
\hline Connectedness & $\begin{array}{l}\text { Peer support } \\
\text { Relationships } \\
\text { Support from others }\end{array}$ \\
\hline $\begin{array}{l}\text { Hope and optimism } \\
\text { about the future }\end{array}$ & $\begin{array}{l}\text { Belief in possibility of recovery } \\
\text { Motivation to change } \\
\text { Hope-inspiring relationships } \\
\text { Positive thinking and valuing success } \\
\text { Having dreams and aspirations }\end{array}$ \\
\hline Identity & $\begin{array}{l}\text { Dimensions of identity } \\
\text { Rebuilding/redefining positive sense of } \\
\text { identity } \\
\text { Overcoming stigma }\end{array}$ \\
\hline Meaning in life & $\begin{array}{l}\text { Meaning of mental illness experiences } \\
\text { Spirituality } \\
\text { Quality of life } \\
\text { Meaningful life and social roles } \\
\text { Meaningful life and social goals } \\
\text { Rebuilding life }\end{array}$ \\
\hline Empowerment & $\begin{array}{l}\text { Personal responsibility } \\
\text { Control over life } \\
\text { Focusing upon strengths }\end{array}$ \\
\hline
\end{tabular}

The question then becomes how to facilitate service users in keeping hope for the future and finding meaning in life. The two (hope finding and meaning giving) are intertwined and can result in experiencing a new quality of life. This is why we (the author who is a researcher; a nurse working as innovator and the photographer) decided to develop an instrument that facilitates the recovery process of persons with SMI and hospitalised on long stay wards. In doing so we could build on findings from earlier research into the therapeutic application of photography in mental health care that confirmed that photographs can trigger a process of moral learning about what a good life means to service users [10].

\section{Methods}

In 2010 we did needs analysis to explore the needs of service users in long stay wards. This analysis was combined with a literature search that was directed by specific issues from the needs analysis. We used the results for designing an intervention.

In 2011 and 2012 we designed an intervention that we followed up by an evaluative action research in which we adapted and fine-tuned the intervention until we were satisfied with the result. This was done conform the steps of an appreciated inquiry (textbox 1). The Appreciative Inquiry (AI) approach was used because it has proved to be an apt instrument for change management in organizations, also in health care $[11,12]$. The basic assumption of $\mathrm{AI}$ is that change is most successful when we build on what works rather than focus on problems. This matches our idea that we should make use of the existing professional routines applied in the rehabilitation approach and its more recent update grounded in the Strengths Approach [2].

Another central component of the AI cycle is its focus on reflexivity and communication between collaborative partners in the research. In this project the collaborative partners were: the researcher, the innovator nurse, the photographer (the project team), the service user and his mentor nurse. The project team invited mentor nurses and team management from three long stay wards to inform service users about the project and to stimulate them to participate when interested. Participants were included on the basis of a pragmatic sample. Participants had to be willing to collaborate with their mentor nurse and the project team. Although this was not formulated as a formal exclusion criterion, participants' psychiatric symptoms were supposed not to interfere with participation in a negative way. We did not aim at influencing psychiatric symptoms or how service users can manage them, neither was improving social skills or the level of daily activities our aim (anyway not in the first place), but finding strengths that inspire hope and meaning giving. That's why the more specific diagnostic psychiatric details were of no direct interest to us and did not matter so much when to decide if someone could participate. What was relevant was the stage of recovery someone was in. 
Service users who were still overwhelmed by acute symptoms or recent crisis may not be stable enough to handle the kind of confrontation that the intervention could mean. This is an assumption however that we chose not to challenge in this development phase.

An informed consent procedure was followed. Ownership of the photographs was settled: service users could decide which photographs were to be selected, and they gave permission to use photographs for educational and scientific purposes. Mentor nurses of service users were asked to participate alongside their clients as we aimed at a learning process for all partners involved. Over a period of two years we organized 15 photo trajectories with service users (and their mentor nurse), sometimes 2 or 3 at the same time and stretching out for a couple of weeks. After completion of every individual trajectory not only the patient's results in terms of recovery were evaluated, but also how things had gone, methodologically. This was done in peer review and notes from logs were used for it. The reflexivity was steered by the evaluation framework we established after a needs analysis (see below: Discover paragraph). Necessary adaptations were carried through at several steps and documented. The service user and mentor nurse were consulted for this evaluation.

An audit trail was planned based on criteria to evaluate the steps in a Development and Evaluation research trajectory of complex interventions using the MRC-guidelines [13].

Textbox 1: Four steps in the Appreciated Inquiry cycle [11]

1. Discover: the identification of organizational processes that work well

2. Dream: the envisioning of processes that would work well in the future

3. Design: the planning and prioritizing of processes that would work well

4. Destiny: the Implementation of the proposed design

\section{Results}

\section{Discover}

In 2010 activities were organised during two or three days in which service users from long stay wards could participate in and enjoy having a massage, being portrayed by a photographer, having one's hair done, etc. ("treat yourself to something nice-days"). The evaluation of these days was the input for an analysis of what sevice users need to go out of the way of normal routine and engage in something new.

From the needs analysis we learnt that people learn from doing things in a kind of trial an error way. They don't give it much thought beforehand, but if they feel attracted somehow to it they then may give it a try. If the activity feels pleasant or reminds them of emotions or values they cherish, then it may trigger further thoughts of engaging in it again. The literature review revealed that a condition for this to happen beside an open and welcoming, non-obligatory setting- is mutuality, the sense of reciprocity and equivalence in the interaction between service users and professionals $[14,15$, 16, 17]. The existence of meaningful relationships contributes to more hope and empowerment [18], and is likely to lead to a better working alliance between caregiver and service user [19]. What we also found was a great need for being recognized as a person, share with others what one feels and thinks and express this. This we had also come across in our earlier research on the therapeutic use of photography [20] and was confirmed again by the observation that having your portrait made was a favorite activity: people lined up for the photographer.

\section{Dream}

Recovery facilitating care is together looking for possibilities and finding starting points in the strength of a person. It departs from a moral appeal not to be lived by one's illness, but salvage a life from the restrictions of mental health disorders. Caregivers can help by recognizing in clients who they potentially are: the authentic person who lays waiting behind the patient and his disturbed behaviour, even where this is only present in potentiality. The role of the caregiver is not that of an expert (anyway not in the first place), but much more that of travelling companion who helps the client to make the journey. The metaphor of a recovery journey was also found in the conceptual framework for personal recovery in mental health that Leamy et al. [1] constructed from a systematic review and narrative synthesis. Promoting the role of travelling companion we hope to contribute to the sense of reciprocity and equivalence between service users and professionals. Caregivers must relinquish the familiar role patterns and undertake this journey together with the client, without knowing on beforehand where they will end or what the outcome will be! If they succeed in doing so then there will be a moment that the client will turn to them for an expert advice how to cope with challenges of the journey. Giving advice uncalled for does not befit a travelling companion, because travelling together suggests a reciprocal relationship. What matters is that caregivers should believe in their client because otherwise they cannot stand beside the client in their search for a life with more quality and more direction.

That's where the shoe pinches however. Most caregivers are inclined to solve problems: the so called reparation reflex. Caregivers offer help where the client asks for it. Treatment plans and nursing plans usually depart from patient problems and shortcomings that need to be repaired or that should at least not become worse. Caregivers therefore think in a problem oriented and problem solving way. This is okay most of the time, especially with clearly defined and delimited problems. However, in the phase of recovery another approach is more fitting, namely one in which the caregiver follows the lead of the client. Of course there is no clear demarcation line between the phase of treatment and a phase of recovery. Recovery starts from the first accommodation and adaptation to a crisis. We cannot say: it is the one or the other. As a caregiver you follow the client 
one moment and the next moment you take the lead.

As a caregiver it remains difficult to detach oneself from the linear problem oriented way of thinking when rehabilitation plans are drafted. Patient's wishes tend to be translated into problems for which goals are formulated and actions to work towards solving these problems. The rational model that characterizes nursing and treatment planning impedes caregivers to think out of the box and approach patient's wishes and ambitions as chances and possibilities that still need to be discovered. They are unable to let go of their impulse to control the situation. Even a method based on the inventory of strengths, the Strengths-approach [2] that nowadays is considered to be a most valuable update of the rehabilitation approach in the Netherlands, runs the risk of ending up in too much talking and planning and too little doing and sharing experiences. However, recovery is a search and a journey of discovery. What a client will discover cannot be predicted on beforehand, let alone that it can be formulated as a goal. What it takes is the will and intention to engage on the journey.

To speak in terms of another metaphor than the image of a journey: it is a dance during which you tune your movement to your dancing partner, alternately leading and then again following. Dancing the tango is something you have to learn. The same goes for supporting someone in his recovery.

\section{Design}

We combined the results from earlier research by the author into hermeneutic photography $[8,10,21,22]$ with experiences with implementation of the Strengths approach [2] in the organisation. The metaphor of a Discovery journey was further developed by us and connected with the need for expressing and sharing one's experiences: why not make a photo report of it? We adopted the idea that a photo report must focus on an inventory of strengths. At first we copied the work sheets from the Strengths approach and had formal planning sessions with service users in order to assess the relevance of the different domains of living and arrive at a prioritizing of some activity to engage in and make photographs of (figure 1). However, we found out that this was not going to work (figure 2). Service users associated this way of going about it with treatment talks and therapy for which they had sometimes developed an allergy over the years (labelled as 'chronic patients' as they were with little perspectives). Reflecting on the guiding principles and concepts while evaluating our proceedings after the first couple of photo trajectories, we concluded that we had to set about it in a different manner. We decided not to depart any longer from first making an inventory of strengths, but to consider this as an outcome of our efforts. First we will create an experience that proceeds from a meeting between the caregiver and the service user in their shared search for sources of strengths. How this can be organized we learnt step by step, sometimes by trial and error and then reflect on our experiences. During the re-iterative reflective reviews the most important question that we asked ourselves was again and again: does the intervention help service users to find out what the good life means for them and can they act upon it in one way or another?
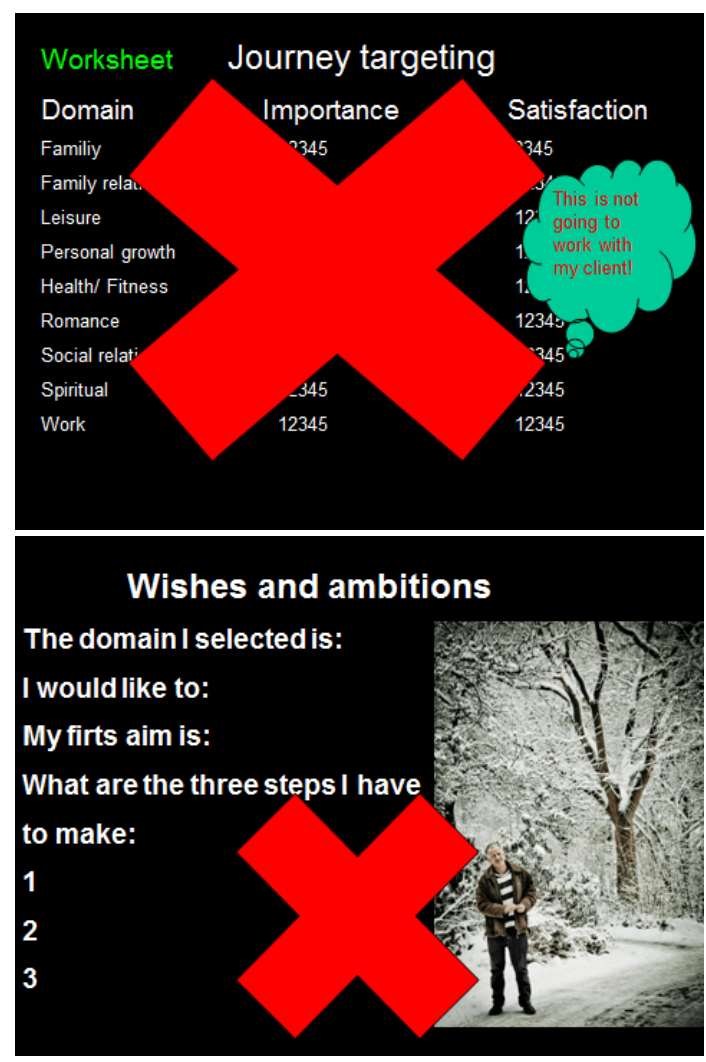

Figure 1. Worksheets from rehabilitation handbook with visuals added as comments.
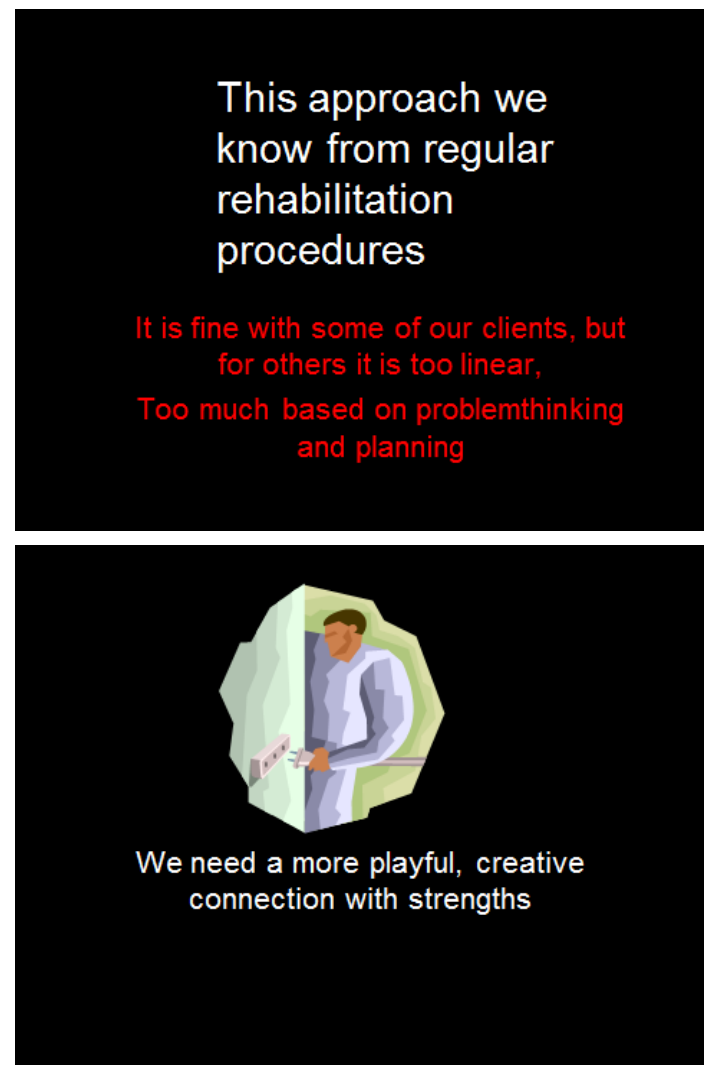

Figure 2. New understanding 
And of course, we realized that, when the journey is undertaken and the travelling companions are on the road, then there may be a moment that they feel the need for making a stop and reflect on what we they have experienced so far and see if the experience inspires the client to wish for follow up activities and may-be even formulate goals to realize them. The client takes direction here and the caregiver follows. The caregiver's role is to create conditions. One of the conditions is to make visible what happens. On crucial moments photographs are made.

\section{How It Is Been Done}

There are four photo sessions. The first session is set for making a photo portrait. The photographer can take out here his equipment and even set up a mobile studio if necessary. This is actually the only time that he is directing the scene. The second session is when the service user lets us in on his daily routine and the photographer will portray him or her in his/her own setting and dwelling. The photographer follows now the service user, the mentor nurse who accompanies the service user and the project staff member. Photographs are now made much more spontaneously, on the spur of the moment. The third session the photographer photographs the service user and the mentor nurse when they engage in an activity in the context of recovery. Photographs are made unobtrusively. The photographer tries to prevent that the sessions become a photoshoot, although he may at times enter upon a dialogue with the client (about what and how to photograph). The fourth and last session focuses on possible gains or results of the activity of the third session. Did the recovery activity effect a change with the client? Did the contact with the mentor nurse or relatives improve? Not necessarily the gain is increased activity or a larger participation in social roles. May-be the most important benefit is that some clients develop a larger self-esteem or found renewed strength to face life. The role of the photographer now is to tune in to the situation and be sensitive for every visual clue that hints at positive feelings or insight/inspiration that the service user may experience.

Clients can engage in the project without precisely knowing what it is that they want to have photographed. They may either choose from three premediated trajectories or propose one of their own. The three given options are the following:

- 'Walking on native soil': return to your roots in the town or village where you spent your youth.

- 'Face up the confrontation': who are you now? Who do you want to be and who do you not want to be or become (not even in your worst nightmare).

- 'What can you mean to others?'(What do I have to offer others in terms of warmth, support, good neighbour-ship or love?)

Together the photographs make a story that shows where someone comes from, what journey was undertaken (activities) and where the journey led the client. This is a report with images that may function as a beacon for the client and that reminds him of his journey and will stimulate further reflection on the things that are important in life. The journey starts with asking oneself one question or, actually a number of questions:

What activities make my life worthwhile?

What makes me feel all right about myself?

What are the things I enjoy most throughout the week?

What helps me feel better when I am down?

These questions precede the second session and invite the service user to join a game of seeing and being seen. The question may change then in:

When I make photographs of the things I enjoy (or that give me strength), then what you see is the following:.........

This becomes the point of departure for the journey: 'This is me!' The client is portrayed in his daily routine: the activities and household chores, the setting where he lives, the hobbies he entertains, etc. During this photography session it often occurs that a client discovers what activity he would like to engage in for the third session. In the third étape of the journey we embroider further on the issue of the good things in life. This entails a question that, as we saw before, can be put in more than one way: it can be formulated as strength, as something that can be enjoyed or that makes you feel good, etc. But we can also put the question as one that inquires after potential possibilities:

Do you have a wish for something that you want to do: may-be something that is on your mind for some time?

Or

Is there something that you have done in the past and that you would like to do again?

Or

What do you like and find important to go for?

It depends on the service user what option will be chosen. He or she is in the lead. During the trajectory the mentor nurse is a facilitator who organizes the activity and finds time to accompany the service user while he or she enjoys it. Sometimes this means that excursions are made to places outside the hospital and that things must be arranged and sometimes funding must be found.

Beside this role as a facilitator the mentor nurse will note down the conversations the service user will engage in, especially the noteworthy things and reflections during the sessions. These notes the nurse will return to the service user afterwards together with prints of the photographs. The service user can decide which photographs will be used for an album and which of the texts can be used to go with the photographs. This usually ensures a kind of dialogue with the mentor nurse and photographer. 


\section{Destiny}

The results were heart-warming. All 15 participants found an activity they engaged in with much enthusiasm (which shows from the photographs). This could vary from taking up badminton, playing pool with a buddy, visiting relatives, picking up a dog at the asylum (and taking it home for keeping) to: visiting a museum, follow art lessons and treat oneself to beauty care, sewing a dress or indulge in shopping. Some of the participants continued with these activities even long after the project had ended.

We witnessed how service users took the lead and surprised us with their vitality and unthought- of talents. William for instance, a 46 year old man, living on the grounds of the institute for over two decades, underwent a metamorphosis the moment we drove into his hometown (where he hadn't been for many years). He became much livelier and directed us to the places where he had lived: his old school, the house where he had lived with his parents and brother and sister, the chapel where he used to come. Not only did we learn much more of his background but we felt a kind of attachment, even felt moved because we came to recognize him as a person with a history. In the chapel, kneeling for Virgin Mary he told us that as a young child he came here every week. Then we realized how lonely life must have been for him, having lost his mother when he was 4 years old. What was before just another fact on the patient chart now became alive and gave a much deeper person-to-person understanding and connection? When we visited his sister we saw how endearing William played with his niece, his sister's grandchild. And we learnt from his sister that William used to be very good at playing badminton. We wondered whether this was something to explore further with William and that is what the mentor nurse did later on.

To find out what is important to you someone must go out of your normal way, and in the case of institutionalized clients, literally away from the terrains of the institute. This journey of discovery contributes to exploring your own roots in a search for who you want to be or what you want to mean as a person to others in this world. Within the context of the photo story this exploration usually keeps a light touch, because it is a game of seeing and being seen. On the more basic level it is about how someone wants to look like. We observed how participants seized upon the opportunity to make a representation of them. It is no coincidence that two of the women had a beauty arrangement, because good looks are important for one's self-esteem.

Photographs offer service users an opportunity to feel accepted for positive valued aspects of their personhood (literally and metaphorically 'seen and not overlooked'). Photo stories were availed to this end by exhibiting them in the residential home or somewhere else (of course with consent from the participants). Some of the photographers guided visiting guests along the photographs on an opening night and explicated their meaning. Besides, clients received their own album and an extra copy to share with relatives.

With the 15 photo-stories we built a professional photo-exhibition with which we toured the country and that has been used as example case in teaching the professionals about recovery facilitating care.
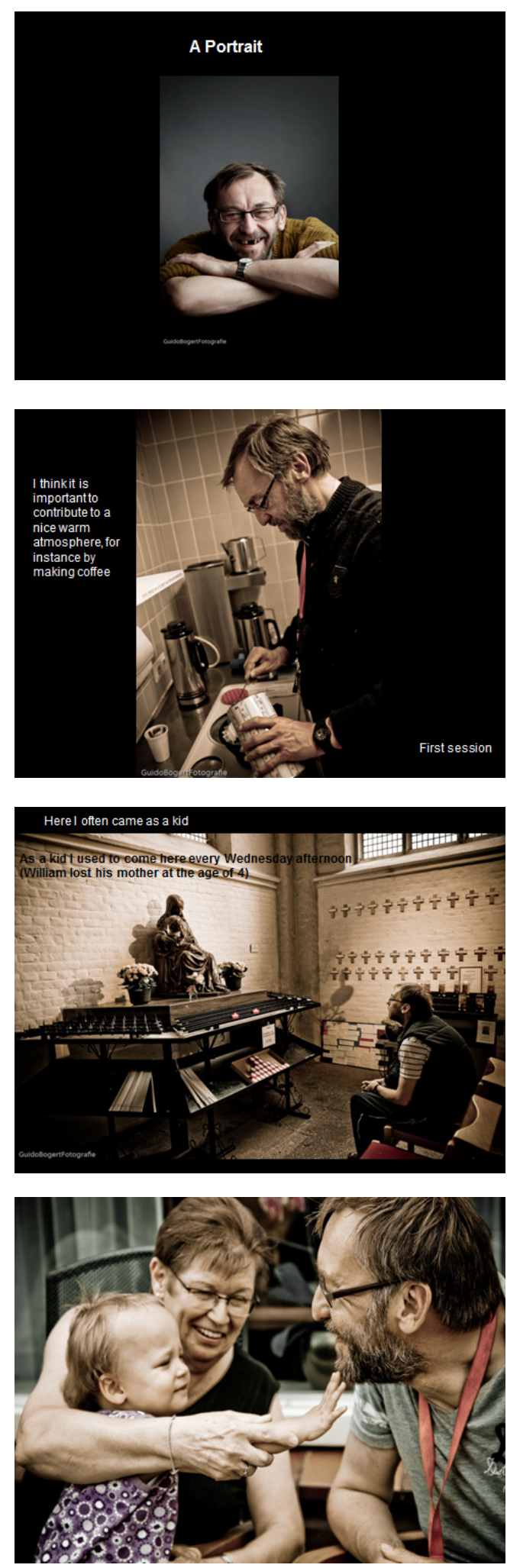

Figure 3. Photographs from exemplary case William

In the project the photographs are made by a professional photographer. However, this may also be done by the 
caregiver himself or by an amateur-photographer who works as a volunteer or by the client himself (as is the case in the photo-instrument: see Author [20]). The project was continued by volunteers from a photo club in the nearby town.

\section{Discussion}

The intervention aimed at helping people to connect with expectations and memories of what they found important in their lives. The message it contains was: get doing what you find important! The only condition we put forward is that it must be a new activity, something that takes guts and courage to overcome reticence to make a first move. We made a demand on service users, expecting them to reach beyond normal routine. We did so because we believe that people can do more than they usually have been demonstrating, pampered as they often are by overprotective caregivers. That's why we asked not only what a client liked to do, but also what he thought is important to him.

It seems that the intervention indeed triggered the necessary willingness to take risks and express wishes that connect the service users with values on a deeper level: for William for instance this was feeling connected with his relatives.

Visualising an activity in the context of recovery promotes expression and ownership. Some of the more expressive images- those invested with pride for instance- may become mental icons that linger on in the mind. In this way they function as reminders that invite clients to follow up the intention associated with the photographed action. They then may become scripts for further recovery. Whether this will actually be the case, must still be investigated in a research with a design to test outcomes based on this assumption.

The project aimed at providing nurses with a method to realize recovery oriented care. We observed that mentor users and other caregivers took what they saw to heart and facilitated the realization of wishes on a more durable basis than the time the project lasted. Did the project also achieve more mutuality and a sense of reciprocity and equivalence in the interaction between service users and their mentor nurses? We believe it did (as we tried to demonstrate with the exemplary case of William), although we haven't examined this systematically and we are not sure whether the relationship remained instilled with this mutuality that we had sensed so strong during the project also after 6 or 12 months.

We viewed recovery within an ecological framework by focusing on the strengths that service users experience in the individual's life context. The intervention contributed to a transformation of environmental factors into opportunities for connecting with other people, even when this is within a service setting. So, where the ground breaking conceptual framework for personal recovery in mental health by Leamy et al. [1] ended with the observation that: "It may therefore be more helpful to undertake evaluative research addressing specific service-level questions (such as whether people using a service are making recovery gains over time) or in different settings rather than further studies seeking conceptual clarity" then that is exactly what we did. This research is about the development and evaluation of an intervention to support the CHIME recovery process. Using the strengths approach we discovered how to make a niche in one of those "different settings", meaning that we optimized the potential good and strengths of the environment (long stay wards) and made it fit the needs of the service users staying there instead of the other way around (service user accommodating themselves to the regime of an institutional setting). This may be deemed to fail on beforehand, because of the location: group residences and sheltered homes segregating people with SMI from the larger community, thus by definition constituting a so called 'entrapping niche' (instead of an enabling niche). It is however not realistic to expect that in future all people with SMI will be able to live in the community and enjoy a quality of life that is the same as it is in institutional residences. If so, then we can better make the best of it and reform these places in more enabling niches, knowing that we must keep striving for more natural niches within the community. So, we entertain a more pragmatic attitude here than Rapp \& Goscha [2] did when they disqualified institutional settings altogether. The discussion is not without urgency as due to budget cuts and policy priorities mental health institutions in The Netherlands must reduce the number of beds with $30 \%$ and municipalities are held responsible for organizing basic care and welfare networks within local neighbourhoods.

This study has its own strengths and limitations. Its strength was the use of the Appreciative cycle in combination with the stages of the MRC-framework. Its focus on transforming communication and on what works directed the research. The reciprocity and equivalence in the interaction between service users and professionals was limited to the intervention itself and did not encompass roles of the service user as co-researcher (although they were consulted for feedback). This we consider as a weakness. We did not perform a feasibility study in which a business case is tested with cost-efficiency as one of its parameters. Neither did we research the degree of effectivity of outcomes. This study is much more a first evaluation in a development process of new interventions.

\section{Conclusions}

The intervention that has been designed and evaluated yielded opportunities for service users to express their wishes and values in life. In this way they made a representation of the persons who they are. The photographs probably contribute to a greater self-esteem of the service users and may inspire them to use the action and what it meant to them for further recovery. The intervention put the service user in the lead and contributed to more mutuality in the relationship with the mentor nurse. 


\section{List with Abbreviations and Acronyms}

AI: Appreciative Inquiry.

CHIME-Framework: Connectedness, Hope, Identity, Meaning in life, Empowerment.

MRC-guidelines: Medical Research Council guidelines

SMI: Severe Mental Illness

\section{Acknowledgements}

There were no industrial links or affiliations. For building an exhibition we were funded by funds, one public and one related to health insurance companies, but this was limited to the exhibition and did not concern the research and development of the intervention. The research was done as part of our job as researcher and innovation staff member in the service of GGnet.

\section{Author Statement}

I am the only author of the manuscript. In the data collection I collaborated with Ingrid Bogert, nurse and innovation staff at GGNet and with Guido Bogert, nurse and photographer, freelancer. The data analysis was done by the author.

\section{Disclosure of Interests}

There is no conflict of interest.

\section{REFERENCES}

[1] Leamy M, Bird V, Le Boutillier C, Williams J, Slade M. A conceptual framework for personal recovery in mental health: systematic review and narrative synthesis. Br. J. Psychiatry 2011; 199: 445-52.

[2] Rapp C.A. \& Goscha RJ. 2006. The Strengths Model. Case Management with People with Psychiatric Disabilities. New York: Oxford University Press, 2006.

[3] Hagedorn M. Photography: an aesthetic technique for Nursing Inquiry. Issues in Mental health Nursing 1996; 17: 517-527.

[4] Sitvast JE \& Abma TA. The photo-instrument as a Health Care Intervention. Health Care Analysis 2012; 20:177-195.

[5] Boevink W., Beuzekom van J. et al. Samen werken aan herstel. Utrecht: Trimbos-instituut, 2003.

[6] Deegan PE. Recovery: The lived experience of rehabilitation. Psychosocial Rehabilitation 1998; 11(4): 11-19.

[7] Corrigan PW. What is the impact of self-stigma? Loss of self-respect and the "why try" effect. World psychiatry 2009; 2: $75-81$.

[8] Sitvast JE, Abma TA. \& Widdershoven GAM. (2011). Living with severe mental illness. The perception of the sickness impact on daily life functioning. Journal of Advanced Nursing 2011; 67 (10): 2170-2197.

[9] Turton P., Wright C., White S., Killaspy H. (2010). Promoting recovery in long-term institutional mental health care: an international Delphi study. Psychiatr. Serv. 61(3): 293-299.

[10] Sitvast JE, Widdershoven GAM. \& Abma TA. (2011). Moral Learning in Psychiatric Rehabilitation. Nursing Ethics 2011;18 (4): 583-595.

[11] Lazic J., Radenovic M., Arnfield A. \& Janic D. Implementation of a nurse education programme in paediatric oncology using appreciative inquiry. A single center experience in Belgrade, Serbia. European Journal of Oncology Nursing 2011; 15 (5): 524-527.

[12] Cooperrider DL. Positive image, positive action: the affirmative basis of organization. In: S. Srivasta \& D.L. Copperrider (eds.), Appreciative management and leadership: the power of positive thought and action in organizations. San Francisco: Jossey-Bass, 1990.

[13] Mohler R. , Bartoszek G., Kopke S. \& Meyer G. Proposed criteria for reporting the development and evaluation of complex intervention in healthcare (CReDECI): guideline development. Int. Journal of Nursing Studies 2012; 49: 40-46.

[14] Slade M. (2013, $2^{\text {nd }}$ edition). 100 Ways to support recovery. A guide for mental health professionals. London: Rethink Mental Illness, 2013.

[15] Davis LW. \& Lysaker PH. Therapeutic alliance and improvements in work performance over time in patients with schizophrenia. The Journal of nervous and mental Diseases 2007; 195: 353-357.

[16] Farkas M. \& Anthony WA. Psychiatric rehabilitation interventions: a review. International Review of Psychiatry 2010; 22: 114-129.

[17] Wilken JP. \& Den Hollander D. Rehabilitation and recovery, a comprehensive approach. Amsterdam (The Netherlands): Uitgevery SWP, 2005.

[18] Hobbs M. \& Baker M. Hope for recovery-How clinicians may facilitate this in their work. Journal of Mental Health 2012; 21: 144-153.

[19] Hicks AL., Deane FP. \& Crowe TP. Change in working alliance and recovery in severe mental illness: an exploratory study. Journal of Mental Health 2012; 21: 127-134.

[20] Sitvast JE. Hermeneutic Photography. An innovative intervention in psychiatric rehabilitation founded on concepts from Ricoeur. Journal of Psychiatric Nursing 2014; 5(1):17-24.

[21] Sitvast JE, Abma TA., Lendemeijer HHGM. \& Widdershoven, GAM. Photostories, Ricoeur and Experiences from Practice. A Hermeneutic Dialogue. Advances in Nursing Science 2008; 31(3): 268-279.

[22] Sitvast JE, Abma TA. \& Widdershoven GAM. Facades of Suffering: Clients's Photo stories About Mental Illness. Archives of Psychiatric Nursing 2010; 24(5): 349-361. 